DOI: $10.17957 / \mathrm{IJAB} / 15.1789$

http://www.fspublishers.org

\title{
Development of a SCAR Marker Based on SCoT Polymorphisms for Sugarcane Smut Resistance
}

\author{
Quanqing Deng ${ }^{1,2 \dagger}$, Han Bao ${ }^{1,2 \dagger}$, Yichang $\mathrm{Cai}^{1,2 \dagger}$, Jia Wu ${ }^{1,2}$, Jianwen Chen ${ }^{1,2}$ and Wankuan Shen ${ }^{1,2,3^{*}}$ \\ ${ }^{1}$ College of Agriculture, South China Agricultural University, Guangzhou, P. R. China \\ ${ }^{2}$ Sugarcane Research Laboratory, South China Agricultural University, Guangzhou, P. R. China \\ ${ }^{3}$ Scientific Observing and Experimental Station of Crop Cultivation in South China, Ministry of Agriculture and Rural Areas, \\ Guangzhou, P. R. China \\ "For correspondence: wkshen69@126.com \\ ${ }^{\dagger}$ Contributed equally to this work and are co-first authors \\ Received 21 January 2021; Accepted 16 March 2021; Published 10 May 2021
}

\begin{abstract}
Sugarcane smut caused by Sporisorium scitanmineum is the most severe sugarcane disease that causes major economic losses in sugarcane production in China, and disease resistance breeding is an important way of preventing and controlling this disease. In this study, $\mathrm{BC}_{3} \mathrm{~F}_{1}$ lines derived from the cross between YC 73-226 and YCE 06-111 were used to generate sugarcane smut-resistant and -susceptible gene pools using bulked segregant analysis (BSA). Eighty-nine random primers of start codon targeted (SCoT) polymorphisms were screened, whereas only primer SCoT44 could stably amplify the specific fragment (HE-Ss44) in the resistant pool. Then, several primer pairs of sequence characterized amplified regions (SCARs) were designed based on the sequence alignment of HE-Ss44 (920 bp), which was recovered after purification, and only one pair of SCAR primers (Ss44-F2/R2, forward: 5'-GGCGGGCACCGTCGAGTCCACAT-3'; reverse: 5'-CCGTCCGTCGG TCTCGTCCTTACG-3') could stably amplify a 400-bp specific band in resistant gene pool and its individuals. A validation test of SCAR marker Ss44-F2/R2 was performed using 34 sugarcane cultivars with known smut resistance, which revealed a selection accuracy of $82.35 \%$ between marker detection and known smut resistance. Moreover, Pearson's correlation analysis also showed that the SCAR marker Ss44-F2/R2 was significantly correlated $(r=0.583, P=0.0003<0.01)$ with the smut resistance trait in sugarcane. In addition, the nucleotide sequence of HE-Ss44 linked with smut-resistance was not aligned to the homologous sequence in GenBank (NCBI), and the accession number was MG740763. The SCAR marker Ss44-F2/R2 developed in this study can be used for the rapid detection of smut resistance in sugarcane and may be utilized as reference for the improvement of sugarcane smut resistance based on molecular marker-assisted selection. (C) 2021 Friends Science Publishers
\end{abstract}

Keywords: Sugarcane; Sporisorium scitanmineum; Bulked segregant analysis; Start codon targeted markers; Sequence characterized amplified region markers

\section{Introduction}

Sugarcane (Saccharum hybrids spp.) is an important sugar crop and a renewable biomass energy crop. Sugarcane is distributed in tropical and subtropical regions, with many types of diseases and heavy hazards. Sugarcane smut caused by Sporisorium scitanmineum is a global sugarcane disease. Sugarcane smut was first reported in Natal, South Africa, in 1877 and is now widely occurring in sugarcane-growing areas around the world, resulting in a significant decrease in yield of up to $30 \%$ and reduced sucrose content (Izadi and Moosawijorf 2007; Nzioki et al. 2010; Viswanathan and Rao (2011). China first reported the occurrence of sugarcane smut in Guangzhou in 1934 (Antoine 1961). In the past 20 years, sugarcane smut has become more harmful in China's sugarcane growing areas due to long-term singular planting, physiological race differentiation of S. scitanmineum, and dry cultivation ( $\mathrm{Xu}$ et al. 2017). Sugarcane smut has become the most economically harmful sugarcane disease in China's sugarcane production, causing direct economic losses of 750 million dollars per year (Chen et al. 2016).

Actual sugarcane production has proven that breedingresistant varieties of sugarcane smut are the most economical and effective way to control the disease (Shen $e t$ al. 2014). The identification of smut resistance is an important part of sugarcane breeding, and the traditional identification method of sugarcane smut resistance involves phenotypic identification by artificial inoculation. However, this method is generally time and energy consuming, and it is difficult to evaluate disease resistance of the sample on a

To cite this paper: Deng Q, H Bao, Y Cai, J Wu, J Chen, W Shen (2021). Development of a SCAR marker based on SCoT polymorphisms for sugarcane smut resistance. Intl J Agric Biol 25:1272-1280 
large scale, and the identification results are also affected by environmental interaction effects (Chen et al. 2017). Marker assisted selection (MAS) is not affected by genotype and environment interactions and can significantly improve the selection efficiency and accuracy of disease-resistant breeding when combined with routine identification methods, although selection accuracy requires molecular markers that are closely linked to target traits (Lee 1995; Collard and Mackill 2007). Saccharum and related genera with extremely complex genomes are highly heterozygous heteropolyploids or aneuploids (Zhang et al. 2018), and thus quantitative trait locus (QTL) is not suitable for the development of sugarcane molecular markers. Bulked segregant analysis (BSA) was first described by Michelmore and Kesseli (1991) and used in screening for molecular markers that are linked to the downy mildew resistance gene in lettuce. BSA can rapidly and efficiently find markers that are linked to target traits (Cheng et al. 2016) and is particularly suitable for crops such as sugarcane, which are difficult to obtain near-isogenie lines (NIL) and double haploid (DH) populations. Khan et al. (2017) used BSA combined with RAPD molecular marker technology to obtain a specific polymorphic marker that is linked to a smut-resistant gene and converted it into a stable SCAR marker and then further verified the marker accuracy of seven sugarcane varieties with known resistance in Pakistan, and the results were basically consistent. However, the BSA marker analysis population of Khan et al. (2017) was not derived from the same cross combination which may weak the accuracy of the target marker. In this study, a sugarcane smut-resistant population was constructed by the progeny of the same sugarcane hybrid combination and then used to screen the appropriate molecular markers that are closely linked to the sugarcane smut-resistant gene.

The start codon targeted (SCoT) polymorphism, which was developed by Collard and Mackill (2007), is a target gene marker technology based on translation initiation sites. Due to its simplicity of operation, low cost, rich polymorphism, and good repeatability, this technology has been successfully applied to various investigations such as genetic diversity (Shen et al. 2016; Shekhawat et al. 2018), population structure analysis (Tiwari et al. 2016; Golkar and Nourbakhsh 2019) and disease resistance (Zeng et al. 2014; Li et al. 2019). In addition, the primer length of SCoT is 18 bp, with the same reaction conditions as conventional PCR, although with higher stability (Shen et al. 2016; Chen et al. 2017). No study on the development of sugarcane smut resistance markers based on SCoT molecular marker technology combined with BSA analysis population has been conducted to date.

In this study, the intergeneric hybridization progeny $\mathrm{BC}_{3} \mathrm{~F}_{1}$ lines from the same cross combination (YC 73-226 $\times$ YCE 06-111) were used as the test materials, and the artificial inoculation method was used to identify the resistance of test materials to sugarcane smut. Based on their reaction to sugarcane smut, a BSA analysis population of sugarcane resistance to smut was constructed, and SCoT molecular marker technology was combined to screen specific polymorphic markers that were closely linked to the smut resistance gene in sugarcane. Furthermore, SCoT markers can be transformed into stable SCAR markers, which in turn may be utilized in molecular marker-assisted breeding for sugarcane smut resistance.

\section{Materials and Methods}

\section{Plant materials}

Eighty hybrid $\mathrm{BC}_{3} \mathrm{~F}_{1}$ lines derived from the sugarcane cross combination YC 73-226 (susceptible) $\times$ YCE 06-111 (resistant) were evaluated by artificial dip inoculation of sugarcane smut using method of Dou et al. (2017). Two bulked gene pools (resistant and susceptible gene pool) were constructed respectively by five highly resistant and five highly susceptible or susceptible lines which were screened after smut-resistant evaluation (Table 1). The 34 sugarcane cultivars with known smut resistance (identified by artificial dip inoculation or confirmed by field performance) were used as controls to verify the reliability of the SCAR markers developed in this study (Table 2) (Shen et al. 2012; Chen et al. 2016).

\section{Genomic DNA extraction and bulk construction}

Fresh heart leaves of the test materials were collected and genomic DNA extraction was performed using CTAB (Shen et al. 2006). The concentration and purity of DNA were measured using the ultramicro-ultraviolet spectrophotometer NanoDrop ND-1000 (Thermo Fischer Scientific, Wilmington, DC, USA). Then, the concentration of all DNA samples was normalized to $50 \mathrm{ng} / \mu \mathrm{L}$ and stored at $-20^{\circ} \mathrm{C}$ until use.

According to the construction principle of BSA (Michelmore and Kesseli 1991; Khan et al. 2017), the genomic DNA of different lines with the particular trait (i.e., response to smut in this study) was mixed in equal amounts to construct two bulked pools, i.e., the smut-resistant pool included five highly resistant lines (HE15-17, HE15-33, HE15-62, HE15-81, and HE15-87) and the smut-susceptible pool comprised three highly susceptible and two susceptible lines (HE15-10, HE15-50, HE15-68, HE15-63, and HE1580) (Table 1).

\section{SCoT primers and PCR amplification}

Following the previous studies (Collard and Mackill 2007; Luo et al. 2010; Gao et al. 2014), a total of 89 SCoT primers, synthesized by the Sangon Biotech (Shanghai, China) Co., Ltd., were used for an initial primer screen. The PCR reactions were conducted in a total volume of $25 \mu \mathrm{L}$ containing $1.0 \mu \mathrm{L}$ (150 200 ng) DNA template, $0.4 \mu \mathrm{L}$ of Taq DNA polymerase (5.0 U/ $\mu \mathrm{L})$ (TaKaRa cat \# R001A), 2.5 
$\mu \mathrm{L}$ of $10 \times$ PCR buffer $\left(\mathrm{Mg}^{2+}\right), 2.0 \mu \mathrm{L}$ of dNTP mixture $(2.5$ $\mathrm{m} M), \quad 1.0 \mu \mathrm{L}$ of SCoT primer $(10.0 \mu \mathrm{M})$, and finally supplemented with $18.1 \mu \mathrm{L}$ of sterile double distilled water. Amplification was performed using the following PCR program: $5 \mathrm{~min}$ at $94^{\circ} \mathrm{C}$; followed by 35 cycles of $45 \mathrm{~s}$ at $94^{\circ} \mathrm{C}, 50 \mathrm{~s}$ at $50-60^{\circ} \mathrm{C}$ (depending on the annealing temperature of each primer), $2 \mathrm{~min}$ at $72^{\circ} \mathrm{C}$; and a final extension at $72^{\circ} \mathrm{C}$ for $8 \mathrm{~min}$. The above amplification reaction was conducted using a Mycycler Thermal Cycler PCR Amplifier (Bio-Rad, USA). The $6-\mu \mathrm{L}$ PCR products with the marker DL 2000 DNA (TaKaRa Cat \# 3427A) were electrophoresed on a $1 \%(\mathrm{w} / \mathrm{v})$ agarose gel using 1.0× TAE buffer at $85 \mathrm{~V}$ for $45 \mathrm{~min}$. The separated DNA fragments were stained with $0.5 \%$ GoldView $^{\mathrm{TM}}$ and photographed using a gel imaging system (Tanon 1600, Shanghai).

\section{SCoT primer screening and validation}

The SCoT primers that generated polymorphic fragments in two bulk pools were first screened using the established SCoT-PCR (Chen et al. 2017). Then, further testing of the selected primers using 10 lines (individuals in pools) was performed, and 34 control cultivars were assessed for primer polymorphisms and the specific fragment was obtained that was amplified only in the smut-resistant or susceptible materials. The experiments were repeated at least thrice.

\section{TA clone sequencing of specific SCoT fragments}

The specifically amplified SCoT fragment was excised from the $1 \%$ agarose gel and purified using a SanPrep Column DNA Gel Recovery Kit (Cat \# SK8131 Sangon Biotech, Shanghai, China). TA clone sequencing of this fragment was commissioned by Sangon Biotech (Shanghai, China) Co., Ltd. Then, sequence alignment was performed in GenBank (NCBI), and DNA Star (5.01) MegAlign was used in sequence analysis.

\section{SCAR primer design and PCR amplification}

Based on the sequence of HE-Ss44, SCAR primer pairs, synthesized by Sangon Biotech (Shanghai, China) Co., Ltd., were designed via DNAStar (5.01). The DNA template used for SCAR-PCR was identical to SCoT-PCR. The PCR reactions were conducted in a total volume of $25 \mu \mathrm{L}$ containing $1.5 \mu \mathrm{L}(150 \sim 200 \mathrm{ng})$ DNA template, $12.5 \mu \mathrm{L}$ of Green Taq Mix (Cat \# P131-01 Vazyme Biotech Co., Ltd.), $0.5 \mu \mathrm{L}$ of forward primer $(10.0 \mu \mathrm{M}), 0.5 \mu \mathrm{L}$ of reverse primer $(10.0 \mu \mathrm{M})$, and finally supplemented with $10.0 \mu \mathrm{L}$ of sterile double distilled water. The amplification was performed using the following PCR program: $3 \mathrm{~min}$ at $95^{\circ} \mathrm{C}$; followed by 35 cycles of $15 \mathrm{~s}$ at $95^{\circ} \mathrm{C}, 15 \mathrm{~s}$ at $70^{\circ} \mathrm{C}$, $24 \mathrm{~s}$ at $72^{\circ} \mathrm{C}$, and a final extension at $72^{\circ} \mathrm{C}$ for $5 \mathrm{~min}$. The above amplification reaction was conducted on a Mycycler Thermal Cycler PCR Amplifier (Bio-Rad, USA). The $6 \mu \mathrm{L}$
PCR products with the marker DL 2000 DNA (TaKaRa cat \# 3427A) were electrophoresed on a $1 \%(\mathrm{w} / \mathrm{v})$ agarose gel using 1.0 $\times$ TAE buffer at $85 \mathrm{~V}$ for $45 \mathrm{~min}$. The separated DNA fragments were stained with $0.5 \%$ GoldView $^{\mathrm{TM}}$ and photographed under a gel imaging system (Tanon 1600, Shanghai, China).

\section{SCAR primer screening and validation}

The SCAR primers that produced specific bands and were linked to smut disease resistance or susceptible genes in two bulk pools were first screened using the established SCARPCR. Then, further testing of the selected primers in 10 lines (individuals in pools) was performed, and in 34 control cultivars to verify the specificity of the selected primers. The experiments were repeated at least thrice.

The specific SCAR fragment was excised from the 1\% agarose gel and purified using a SanPrep Column DNA Gel Recovery Kit (Cat \# SK8131 Sangon Biotech, Shanghai, China). The TA clone sequencing of this fragment was commissioned to Sangon Biotech (Shanghai, China) Co., Ltd. After sequencing, the specific SCAR fragment was aligned to the SCoT fragment (HE-Ss44) using DNAStar (5.01) MegAlign to verify homology.

\section{Analysis of correlation between SCAR marker validation and known resistance}

The sugarcane cultivars or lines with the same results of SCAR marker detection and known resistance were recorded as " 1 ," and inconsistencies were recorded as " 0 " (Benin et al. 2012; Shan et al. 2018). Pearson's correlation analysis was used to analyze the correlation between the known resistance and the SCAR marker detection results (i.e., 10 hybrids $\mathrm{BC}_{3} \mathrm{~F}_{1}$ lines and 34 control sugarcane cultivars) using IBM SPSS V. 19.0 statistical software.

\section{Results}

Screening and validation of specific SCoT fragment linked to smut resistance

After screening 89 SCoT primers, 13 primers that produced reproducible polymorphisms between the two bulk pools (resistant, susceptible) were selected and used to amplify individuals in each pool. Only the random primer SCoT44 (5'-CAATGGCTACCACTAGCG-3') not only produced polymorphic bands in the smut-resistant pool (Fig. 1A) but also produced a 920-bp specific band (HE-Ss44) in each of the five homozygous-resistant pool individual lines (Fig. 1B). Although the smut-susceptible pool and each of the five homozygous susceptible pool individual lines (three highly susceptible and two susceptible individuals) could produce polymorphisms, these failed to amplify HE-Ss44 (Fig. 1A, B).

Then, further validation of SCoT44 was performed in 
Table 1: Parentage and smut disease responses of various sugarcane lines. Abbreviations: HR, Highly resistant; HS, Highly susceptible; S, Susceptible; MS, Moderately susceptible

\begin{tabular}{lll}
\hline Line & Parentage & Smut disease reaction \\
\hline HE15-17 & YC 73-226 $\times$ YCE 06-111 & HR \\
HE15-33 & & HR \\
HE15-62 & & HR \\
HE15-81 & & HR \\
HE15-87 & & HR \\
HE15-10 & HS \\
HE15-50 & HS \\
HE15-68 & HS \\
HE15-63 & S \\
HE15-80 & & S \\
\hline
\end{tabular}

Table 2: The information of sugarcane cultivars used in marker validation experiments

\begin{tabular}{|c|c|c|}
\hline Cultivar & Origin & Smut disease reaction \\
\hline Badila & Australia & $\mathrm{S}$ \\
\hline CP65-357 & America & $\mathrm{S}$ \\
\hline CP89--2143 & America & MS \\
\hline СР93-1382 & America & $\mathrm{R}$ \\
\hline F134 & Taiwan/China & $\mathrm{S}$ \\
\hline F177 & Taiwan/China & MS \\
\hline GT94-119 & Guangxi/China & $\mathrm{S}$ \\
\hline НоСР95-988 & America & MS \\
\hline LC05-136 & Guangxi/China & $\mathrm{S}$ \\
\hline NCo310 & South Africa & $\mathrm{S}$ \\
\hline NCo376 & South Africa & $\mathrm{R}$ \\
\hline Q157 & Australia & HS \\
\hline Q171 & Australia & HR \\
\hline Q179 & Australia & MS \\
\hline Q189 & Australia & $\mathrm{S}$ \\
\hline Q190 & Australia & HR \\
\hline Q200B & Australia & $\mathrm{R}$ \\
\hline Q205 & Australia & $\mathrm{S}$ \\
\hline ROC5 & Taiwan/China & $\mathrm{R}$ \\
\hline ROC10 & Taiwan/China & HS \\
\hline ROC16 & Taiwan/China & MS \\
\hline ROC20 & Taiwan/China & $\mathrm{S}$ \\
\hline ROC22 & Taiwan/China & HS \\
\hline ROC25 & Taiwan/China & MS \\
\hline TC21 & Sichuan/China & $\mathrm{R}$ \\
\hline YC71-374 & Hainan/China & $\mathrm{S}$ \\
\hline YC73-226 & Hainan/China & $\mathrm{S}$ \\
\hline YT89-113 & Guangdong/China & $\mathrm{S}$ \\
\hline YT91--976 & Guangdong/China & $\mathrm{S}$ \\
\hline YT91-1102 & Guangdong/China & MS \\
\hline YT93-159 & Guangdong/China & $\mathrm{S}$ \\
\hline YT96--86 & Guangdong/China & MR \\
\hline YT02--305 & Guangdong/China & HS \\
\hline B618 & Brazil & MR \\
\hline
\end{tabular}

Abbreviations: R, Resistant; MR, Moderately resistant; HS, Highly susceptible; S, Susceptible; MS, Moderately susceptible

34 control cultivars outside the bulked pools to assess primer polymorphism and specificity. Among these, 11 cultivars (seven smut-resistant cultivars, i.e., CP93-1382, NCo376, Q171, Q190, TC21, YT96-86, and B618, and four smut-susceptible cultivars, i.e., F134, NCo310, Q157 and YC71-374) (Fig. 1C-F) could amplify HE-Ss44. In addition, the other 21 smut-susceptible cultivars (i.e., Badila, CP65-357, CP89-2143, F177, GT94-119, HoCP95988, LC05-136, Q179, Q189, Q205, ROC10, ROC16, ROC20, ROC22, ROC25, YC73-226, YT89-113, YT91-
976, YT91-1102, YT93-159 and YT02-305) and two smutresistant cultivars (i.e., Q200B and ROC5) failed to amplify the band. The above amplification reactions were repeated thrice, and the results were consistent, indicating that the marker generated reproducible results. The verification results confirmed the correlation between HE-Ss44 and smut resistance gene.

The HE-Ss44 was gel purified and subjected to TA clone sequencing. The fragment was $920 \mathrm{bp}$ in size, and the 18 bases of the $5^{\prime}$ and $3^{\prime}$ ends of this sequence were identical to SCoT44, demonstrating that the TA clone sequencing results were accurate (Fig. 2). The sequence of HE-Ss44 was deposited in GenBank (NCBI; GenBank Accession Number MG740763.1), which showed low homology with other known sequences.

\section{Conversion and validation of SCAR markers}

To convert the random SCoT markers into convenient SCAR markers, two specific PCR primers (forward and reverse primers, target size 20-24 bp) were designed according to the sequence of HE-Ss44. First, according to the terminal bases (i.e., the SCoT44 primer with a length of 18 bp) of HE-Ss $44,2-6$ bases were extended inward to constitute the forward and reverse primers. However, these primers produced polymorphic fragments in both gene pools and individuals in the pool (Fig. 3A, B). Furthermore, several primer pairs were designed according to other sequences of the HE-Ss44 fragment, but most of the primer pairs amplified a non-specific single band (i.e., similar amplification could be produced in two bulked pools and the pool individuals) (Fig. 3C, D). Fortunately, primer pair Ss44-F2/Ss44-R2 (Fig. 2) was finally screened to amplify a single specific band of about $400 \mathrm{bp}$ in the smut-resistant pool and five pool individual lines (Fig. 4A). The results of SCAR marker detection showed $100 \%$ concordance with the resistance identification results of individuals in two pools by artificial inoculation, and the correlation coefficient $r$ was 1 .

Based on 34 control cultivars with known smut resistance, the accuracy of primer pair Ss44-F2/R2 was verified. The validation results of the SCAR primers were consistent with primer SCoT44, i.e., 11 control cultivars (seven smut-resistant and four smut-susceptible cultivars) amplified a single 400-bp band (Fig. 4B-E). Moreover, the other 21 susceptible and two resistant control cultivars failed to amplify this band. Then, these single 400-bp target bands were gel-purified and subjected to TA clone sequencing. Sequence alignment confirmed that the nucleotide sequence of the single bands was identical to HE-Ss44 (Fig. 2). The detection results of smut resistance by SCAR marker developed in this study were $82.35 \%$ concordant with their known resistance level to smut in the 34 control cultivars listed in Table 2 , and a significant correlation between them was observed $(r=0.583, P=$ $0.0003<0.01)$. 

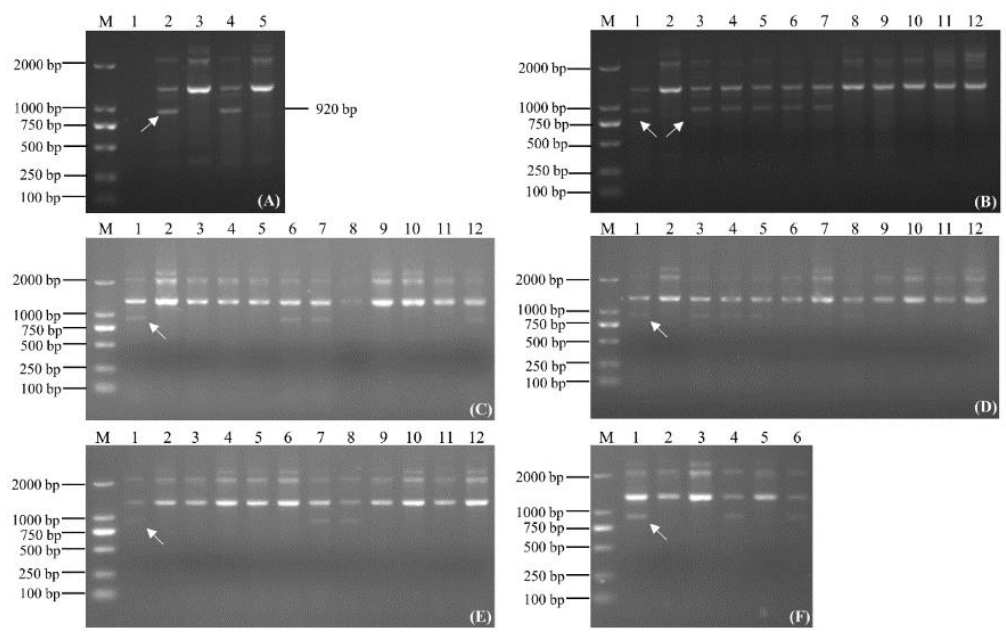

Fig. 1: Amplification profiles of primer SCoT44 from two bulked DNA samples (A), 10 sugarcane lines (B) and 34 sugarcane cultivars bred in China and other countries $(\mathbf{C}-\mathbf{F})$ in 1\% agarose gel electrophoresis. (A) M: DL2000 DNA marker; Lane 1: negative control; Lanes 2 and 4: resistant DNA bulk; Lanes 3 and 5: susceptible DNA bulk. (B) M: DL2000 DNA marker; Lanes 1 and 2: resistant and susceptible DNA bulk; Lanes 3-6: five sugarcane lines with high resistance to smut (HE15-17, HE15-33, HE15-62, HE15-81, and HE15-87); Lanes 8-12: five sugarcane lines, including three highly susceptible to smut (HE15-68, HE15-50, and HE15-10) and two susceptible to smut (HE15-63 and HE15-80). (C) M: DL2000 DNA marker; Lanes 1 and 2: resistant and susceptible DNA bulk; Lanes 3-12: Badila(S), CP65-357(S), CP89-2143(MS), CP93-1382(R), F134(S), F177(MS), GT94-119(S), HoCP95-988(MS), LC05-136(S), NCo310(S). (D) M: DL2000 DNA marker; Lanes 1 and 2: resistant and susceptible DNA bulk; Lanes 3-12: NCo376(R), Q157(HS), Q171(HR), Q179(MS), Q189(S), Q190(HR), Q200B(R), Q205(S), ROC5(R), ROC10(HS). (E) M: DL2000 DNA marker; Lanes 1 and 2: resistant and susceptible DNA bulk; Lanes 3-12: ROC16(MS), ROC20(S), ROC22(HS), ROC25(MS), TC21(R), YC71-374(S), YC73-226(S), YT89-113(S), YT91-976(S), YT91-1102(MS). (F) M: DL2000 DNA marker; Lanes 1 and 2: resistant and susceptible DNA bulk; Lanes 3-6: YT93-159(S), YT96-86(MR), YT02-305(HS), B618(MR). HR: highly resistant to smut; R: resistant to smut; MR: moderately resistant to smut; S: susceptible to smut; MS: moderately susceptible to smut; HS: highly susceptible to smut

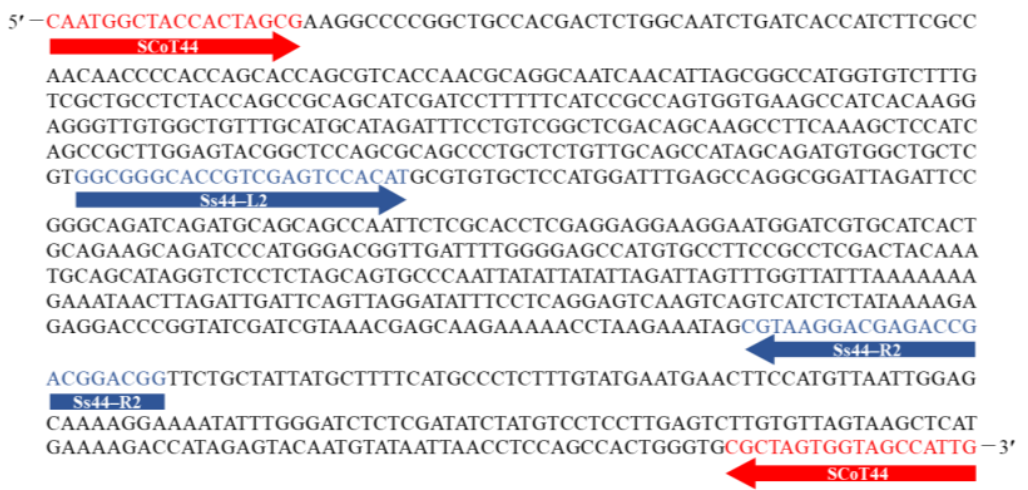

Fig. 2: Nucleotide sequence of HE-Ss44 marker and SCAR primer design. The nucleotide sequence and the arrows marked in red are the nucleotide sequence and position of primer SCoT44, respectively; the nucleotide sequence and the arrows marked in blue are the nucleotide sequence and position of the SCAR primer pairs Ss44-F2 (forward)/Ss44-R2 (reverse), respectively

\section{Discussion}

The sugarcane smut resistance trait, which is controlled by both the host gene and the minor-polygene accumulation, is a qualitative-quantitative trait, and the resistance level of this trait is affected by factors such as environment, host, and pathogeny, and thus resistance identification requires several years of repetition to improve the reliability of the results (Wu et al. 1988; Sundar et al. 2012). Therefore, the identification of sugarcane resistance to smut is generally tedious, and the accuracy of identification results requires improvement. Molecular markers linked to host resistance genes have many advantages such as no environmental impact, rapidity, simplicity, and low cost. It is a key research direction for improving sugarcane varieties resistant to smut.

The acquisition of molecular markers closely linked to target traits or genes is the basis of molecular markerassisted breeding. The combination of molecular markers such as RAPD, SSR, ISSR, and AFLP with BSA has largely contributed to the development of molecular 


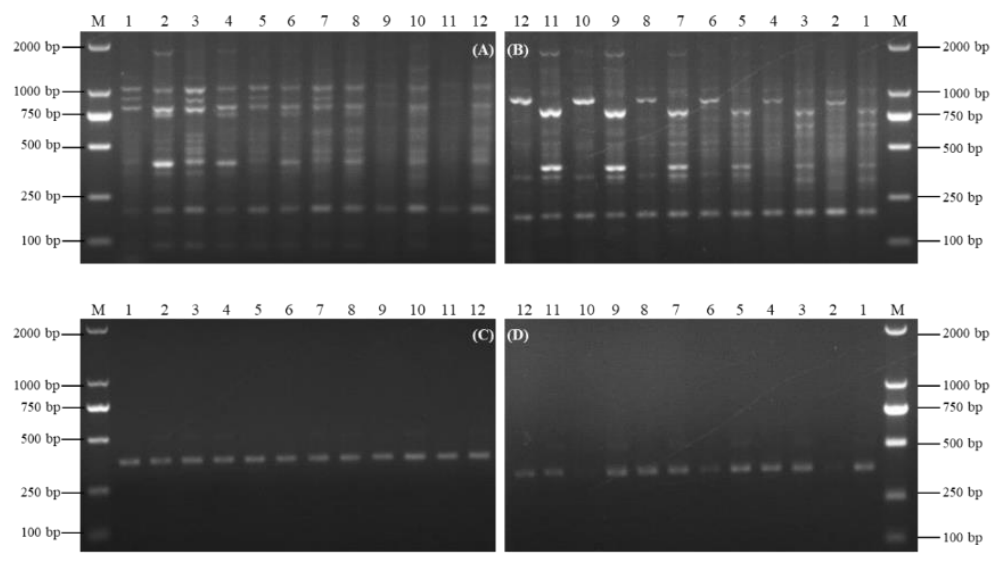

Fig. 3: Amplification profiles of four pairs of unsuccessful primers on two DNA bulks (resistant DNA bulk and susceptible DNA bulk) along with their individual DNA samples in 1\% agarose gel electrophoresis. (A) and (B) display amplified polymorphic fragments; (C) and (D) display non-specific amplified fragments. M: DL 2000 DNA marker; Lane 1: resistant DNA bulk, Lane 2: susceptible bulk; Lane 3: HE15-17 (HR); Lane 4: HE15-10 (HS); Lane 5: HE15-33 (HR); Lane 6: HE15-50 (HS); Lane 7: HE15-62 (HR); Lane 8: HE15-68 (HS); Lane 9: HE15-81 (HR); Lane 10: HE15-63 (S); Lane 11: HE15-87 (HR); Lane 12: HE15-80 (S). HR: highly resistant to smut; HS: highly susceptible to smut; $\mathrm{S}$ : susceptible to smut

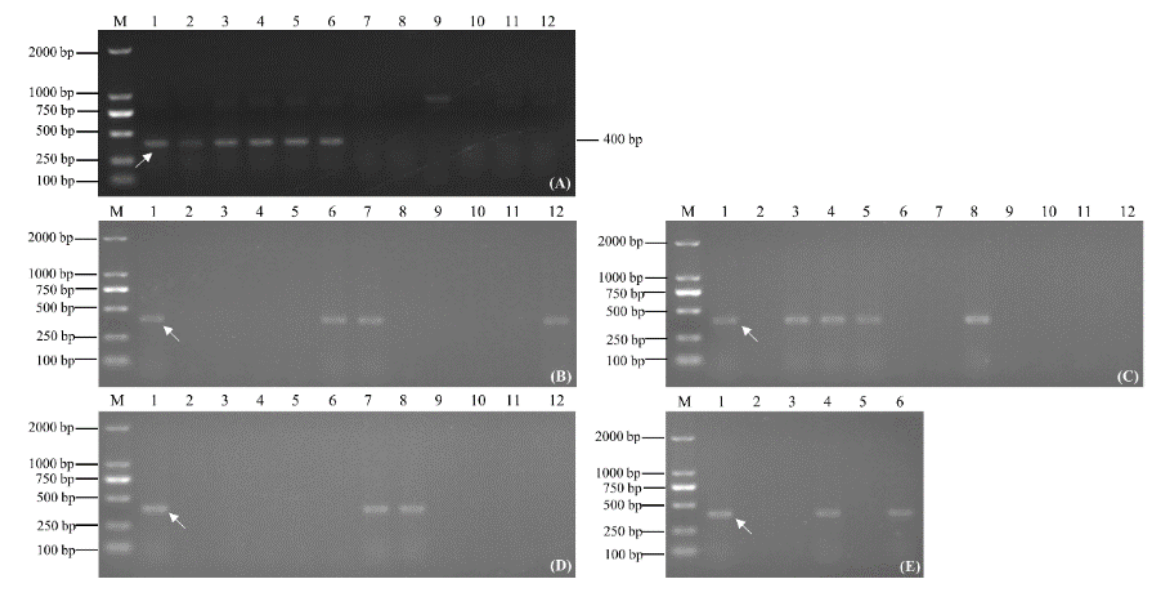

Fig. 4: Verification test of the developed SCAR primer pair Ss44-L2/Ss44-R2 on two DNA bulks (resistant DNA bulk and susceptible DNA bulk) along with their respective DNA samples (A) and 34 sugarcane cultivars as controls (B-E) by PCR amplification in $1 \%$ agarose gel electrophoresis. (A) M: DL2000 DNA marker; Lanes 1-6: resistant DNA bulk and five sugarcane lines with high resistance to smut (HE15-17, HE15-33, HE15-62, HE15-81, and HE15-87); Lanes 7-12: susceptible DNA bulk and five sugarcane lines, including three highly susceptible to smut (HE15-68, HE15-50, and HE15-10) and two susceptible to smut (HE15-63 and HE15-80). (B) M: DL2000 DNA marker; Lanes 1 and 2: resistant and susceptible DNA bulk; Lanes 3-12: Badila(S), CP65-357(S), CP89-2143(MS), CP93-1382(R), F134(S), F177(MS), GT94-119(S), HoCP95-988(MS), LC05-136(S), NCo310(S). (C) M: DL2000 DNA marker; Lanes 1 and 2: resistant and susceptible DNA bulk; Lanes 3-12: NCo376(R), Q157(HS), Q171(HR), Q179(MS), Q189(S), Q190(HR), Q200B(R), Q205(S), ROC5(R), ROC10(HS). (D) M: DL2000 DNA marker; Lanes 1 and 2: resistant and susceptible DNA bulk; Lanes 3-12: ROC16(MS), ROC20(S), ROC22(HS), ROC25(MS), TC21(R), YC71-374(S), YC73-226(S), YT89-113(S), YT91-976(S), YT91-1102(MS). (E) M: DL2000 DNA marker; Lanes 1 and 2: resistant and susceptible DNA bulk; Lanes 3-6: YT93-159(S), YT96-86(MR), YT02-305(HS), B618(MR). HR: highly resistant to smut; R: resistant to smut; MR: moderately resistant to smut; S: susceptible to smut; MS: moderately susceptible to smut; HS: highly susceptible to smut

marker-assisted breeding technology. Akano et al. (2002) screened the marker SSRY28 linked to cassava mosaic disease resistance by SSR markers combined with BSA analysis. Khampila et al. (2008) used RAPD combined with BSA to screen for RAPD markers of waxy corn leaf blight resistance and transformed these into SCAR markers. Brito et al. (2010) used AFLP combined with BSA to screen the first leaf rust resistance marker of coffee Hibrido de Timor. $\mathrm{Xu}$ et al. (2014) used ISSR markers combined with BSA analysis to screen SRAP markers for downy mildew resistance of radish. SCoT based on single-primer PCR amplification is a novel molecular marker technology with 
the advantages of simple operation, low cost, rich polymorphism, and good repeatability (Collard and Mackill 2007; Mulpuri et al. 2013; Feng et al. 2018); its polymorphism is superior to ISSR or SSR, stability or repeatability is superior to RAPD, and cost is significantly lower than AFLP. In the development of markers linked to target traits, the combination of SCoT molecular markers and BSA analysis is a better choice. Hao et al. (2018) successfully developed a SCAR marker for rapid authentication of Taxus media using SCoT markers. Feng et al. (2018) also screened for accurate identification of SCoT markers in Physalis spp. and converted these to SCAR markers. In this study, SCoT markers for sugarcane smut resistance were the first screened and successfully transformed into stable and single SCAR markers using SCoT markers combined with BSA analysis based on disease-resistant segregated population from the offspring of the same cross combination. The SCAR marker developed in this study was validated in the two gene pools (resistant and susceptible) and their individuals, as well as in 34 control cultivars with known resistance to smut.

The accuracy of assisted selection of target traits by molecular markers is a key factor for the successful application of molecular markers. Although the smutresistant SCAR marker developed in this study has good accuracy $(82.35 \%)$ in the validation test of 34 cultivars with known resistance, some SCAR marker detection results of six control cultivars were discordant to their known resistance (i.e., the SCAR markers of the four known susceptible cultivars F134, NCo310, Q157 and YC71-374 were positive, and two known resistant cultivars Q200B and ROC25 were negative) (Fig. 4B-D). Previous reports have described physiological races or pathogenicity differentiation of S. scitanmineum. In the early 1990s, there were two races of $S$. scitanmineum in mainland China, namely, races 1 and 2 (Leu and Teng 1998), in which NCo310 is susceptible to race 1 but resistant to race 2, whereas F134 is susceptible to race 2 but resistant to race 1 . In recent years, new races or pathogenic strains of $S$. scitanmineum different from the above two races have appeared in mainland China (Shen and Deng 2011; Deng et al. 2018). In this study, the mixed teliospore of $S$. scitanmineum (collected in Zhanjiang, Guangdong, China, in May 2015) was used to artificially inoculate the population materials to determine their resistance to smut disease. However, due to unclear factors such as physiological race information of the mixed teliospores inoculated and physiological race types of resistance or susceptibility in separated populations, the linkage between the smut-resistant SCAR marker developed in this study and the physiological race of the host that was resistant to $S$. scitanmineum requires further investigation. Therefore, the above-mentioned SCAR marker detection results are discordant to its known resistance and may be attributable to the differentiation of physiological races of $S$. scitanmineum, which requires further investigation. Since the identification results of smut resistance are affected by the environment and teliospore sources (Shen et al. 2014; Khan et al. 2017), in developing smut-resistant markers, it is recommended to use teliospores from the same sources to conduct poly-year and multi-place artificial inoculation identification, which determines smut resistance of individuals of bulked pools and validation cultivars. Then, artificial identification results are combined with the poly years and multi-place field resistance performances in teliospore collection locations to comprehensively evaluate smut resistance levels. In addition, it is suggested that multiple resistance linkage markers or functional gene markers for the same target trait should be selected simultaneously to improve the accuracy and reliability of the detection results (Talukder et al. 2014; Ukoskit et al. 2019).

Molecular marker-assisted breeding can greatly improve the efficiency and accuracy of target trait selection in crop variety improvement. Nowadays, some traits such as disease resistance (Daugrois et al. 1996; McNeil et al. 2010), virus resistance (Costet et al. 2012), yield (Aitken et al. 2006), and stem color (Raboin et al. 2006) of sugarcane have been identified using markers. Among these, the marker of sugarcane rust resistance has been applied to the improvement of sugarcane rust-resistant varieties. However, the development of molecular markers for resistance to smut in sugarcane has rarely been reported (Xu and Chen 2004; Khan et al. 2017) and has not been applied in the improvement of sugarcane varieties resistant to smut. The resistance detection results of the bulked pools and their individuals by SCAR marker developed in this study showed $100 \%$ concordance with their known resistance, the coincidence degree of the 34 validation cultivars was $82.35 \%$, and the correlation between the detection results of SCAR markers and known resistance levels was significant. Whether the SCAR marker can be further applied to the MAS of sugarcane smut resistance variety improvement requires further verification.

\section{Conclusion}

To conclude, a sugarcane smut resistance SCoT marker (HE-Ss44) was obtained based on SCoT combined with BSA and successfully converted into a single, stable, and reproducible 400-bp SCAR marker Ss44-F2/R2(5'GGCGGGCACCGTCGAGTCCACAT-3'/5'-CCGTCCGTC GGTCTCGTCCTTACG-3'). The resistance detection results of the bulked pools and their individuals using the SCAR marker showed $100 \%$ concordance with their known resistance, the coincidence degree of the 34 validation cultivars was $82.35 \%$, and the correlation between the detection results of SCAR markers and known resistance levels was significant. The sugarcane smut-resistant SCAR marker developed in this study can be utilized in molecular marker-assisted selection of sugarcane smut-resistant varieties. 


\section{Acknowledgments}

This work was supported by grants from the Earmarked Fund for National Natural Science Foundation of China (31771861), Guangdong Provincial Team of Technical System Innovation for Sugarcane Sisal Hemp Industry (2019KJ104-07) and Construction of Modern Agricultural Extension System in Guangdong Province of China (2017LM4166).

\section{Author Contributions}

WS conceived and designed the experimental plan. QD, $\mathrm{HB}, \mathrm{YC}$ and JW performed the experiments. QD analyzed the data and wrote the paper. WS and JC revised the paper. All authors read and approved the final version of the paper.

\section{Conflict of Interest}

The authors declare no conflict of interest among them and institutions where the research has been conducted

\section{Data Availability}

We hereby declare that the data relevant to this paper is available and will be provided on request

\section{Ethics Approval}

Not applicable

\section{References}

Aitken KS, PA Jackson, CL McIntyre (2006). Quantitative trait loci identified for sugar related traits in a sugarcane (Saccharum spp.) cultivar $\times$ Saccharum officinarum population. Theor Appl Genet 112:1306-1317

Akano A, A Dixon, C Mba, E Barrera, M Fregene (2002). Genetic mapping of a dominant gene conferring resistance to cassava mosaic disease. Theor Appl Genet 105:521-525

Antoine R, Smut (1961). Sugarcane Diseases of the World, pp:326-354. Martin JP, EV Abbott, CG Hughes (Eds.). Elsevier, Amsterdam, Netherlands

Benin G, G Matei, ACD Oliveira, GO Silva, TR Hagemann, C Lemes da Silva, ES Pagliosa, E Beche (2012). Relationships between four measures of genetic distance and breeding behavior in spring wheat. Genet Mol Res 11:2390-2400

Brito GG, ET Caixeta, AP Gallina, EM Zambolim, L Zambolim, V Diola, ME Loureiro (2010). Inheritance of coffee leaf rust resistance and identification of AFLP markers linked to the resistance gene. Euphytica 173:255-264

Chen S, WK Shen, GH Xu, XM Wu, QQ Deng, ZM Dou (2017). Assessment of genetic relationship and diversity among Chinese sugarcane parental clones using SCoT and ISSR markers. Intl J Agric Biol 19:291-298

Chen S, ZJ Zeng, WK Shen, GH Xu, XM Wu, MZ Luo, PS Chen (2016). Identification and evaluation on sugarcane parents against smut. Acta Agric Bor Sin 31:432-437

Cheng Z, PX Wang, YB Xu (2016). Bulked sample analysis in genetics, genomics and crop improvement. Plant Biotechnol J 14:1941-1955

Collard BC, DJ Mackill (2007). Marker-assisted selection: An approach for precision plant breeding in the twenty-first century. Phil Trans Roy Soc B Biol Sci 363:557-572
Costet L, LM Raboin, M Payet, A D’Hont, S Nibouche (2012). A major quantitative trait allele for resistance to the sugarcane yellow leaf virus (Luteoviridae). Plant Breed 131:637-640

Daugrois JH, L Grivet, D Roques, JY Hoarau, H Lombard, JC Glaszmann, A D'Hont (1996). A putative major gene for rust resistance linked with a RFLP marker in sugarcane cultivar 'R570'. Theor Appl Genet 92:1059-1064

Deng QQ, GH Xu, ZM Dou, WK Shen (2018). Identification of three Sporisorium scitamineum pathogenic races in mainland China. Intl $J$ Agric Biol 20:799-802

Dou ZM, QQ Deng, WK Shen (2017). Evaluation of $\mathrm{BC}_{3} \mathrm{~F}_{1}$ lines from intergeneric cross between Erianthus arundinaceus and Saccharum for resistance to sugarcane smut caused by Sporisorium scitamineum. Intl J Agric Biol 19:1520-1524

Feng SG, YJ Zhu, CL Yu, KL Jiao, MY Jiang, JJ Lu, CJ Shen, QC Ying, HZ Wang (2018). Development of species-specific SCAR markers, based on a SCoT analysis, to authenticate Physalis (Solanaceae) species. Front Genet 9; Article 192

Gao Y, YQ Zhu, Z Tong, Z Xu, X Jiang, C Huang (2014). Analysis of genetic diversity and relationships among genus Lycoris based on start codon targeted (SCoT) marker. Biochem Syst Ecol 57:221-226

Golkar P, V Nourbakhsh (2019). Analysis of genetic diversity and population structure in Nigella sativa L. using agronomic traits and molecular markers (SRAP and SCoT). Ind Crop Prod 130:170-178

Hao J, KL Jiao, CL Yu, H Guo, YJ Zhu, X Yang, SY Zhang, L Zhang, SG Feng, YB Song, M Dong, HZ Wang, CJ Shen (2018). Development of SCoT-based SCAR marker for rapid authentication of Taxus Media. Biochem Genet 56:255-266

Izadi MB, SA Moosawijorf (2007). Isolation and identification of yeast-like and mycelial colonies of Ustilago scitaminea using specific primers. Asian J Plant Sci 6:1137-1142

Khampila J, K Lertrat, W Saksirirat, J Sanitchon, N Muangsan, P Theerakulpisut (2008). Identification of RAPD and SCAR markers linked to northern leaf blight resistance in waxy corn (Zea mays var. ceratina). Euphytica 164:615-625

Khan M, YB Pan, J Iqbal (2017). Development of an RAPD-based SCAR marker for smut disease resistance in commercial sugarcane cultivars of Pakistan. Crop Prot 94:166-172

Lee M (1995). DNA markers and plant breeding programs. Adv Agron 55:265-344

Leu LS, WS Teng (1998). Culmicolous smut of sugarcane in Taiwan (V) two pathogenic strains of Ustilago scitaminea Sydow. In: Proceedings of the Phytopathological Society of Japan, pp:275-279, Tokyo, Japan

Li R, L Fan, J Lin, M Li, S Sui (2019). In vitro mutagenesis followed by polymorphism detection using start codon targeted markers to engineer brown spot resistance in kalanchoe. J Amer Soc Hortic Sci 144:193-200

Luo C, XH He, H Chen, SJ Ou, MP Gao (2010). Analysis of diversity and relationships among mango cultivars using start codon targeted (SCoT) markers. Biochem Syst Ecol 38:1176-1184

McNeil MD, S Hermann, PA Jackson, KS Aitken (2010). Conversion of AFLP markers to high-throughput markers in a complex polyploid, sugarcane. Mol Breed 27:395-407

Michelmore RW, IPV Kesseli (1991). Identification of markers linked to disease-resistance genes by bulked segregant analysis: a rapid method to detect markers in specific genomic regions by using segregating populations. Proc Natl Acad of Sci USA 88:9828-9832

Mulpuri S, T Muddanuru, G Francis (2013). Start codon targeted (SCoT) polymorphism in toxic and non-toxic accessions of Jatropha curcas L. and development of a codominant SCAR marker. Plant Sci 207:117-127

Nzioki HS, JE Jamoza, CO Olweny, JK Rono (2010). Characterization of physiologic races of sugarcane smut (Ustilago scitaminea) in Kenya. Afr J Microbiol Res 16:1694-1697

Raboin LM, KM Oliveira, L Lecunff, H Telismart, D Roques, M Butterfield, JY Hoarau, A D‘Hont (2006). Genetic mapping in sugarcane, a high polyploid, using bi-parental progeny: identification of a gene controlling stalk colour and a new rust resistance gene. Theor Appl Genet 112:1382-1391 
Shan HB, JW Shi, Y Shi (2018). Development and validation of molecular marker for protein content in tetraploid potato tuber. Acta Agron Sin 44:1095-1102

ShekhawatJK, MKRai, NS Shekhawat, V Kataria (2018). Start codon targeted (SCoT) polymorphism for evaluation of genetic diversity of wild population of Maytenusemarginata.Indus Crops Prod 122:202-208

Shen WK, HH Deng (2011). Analysis of results from smut resistant identification in sugarcane varieties introduced. Chin Agric Sci Bull 27:234-238

Shen WK, GH Xu, MZ Luo (2016). Genetic diversity of Sporisorium scitamineum in mainland China assessed by SCoT analysis. Trop Plant Pathol 41:288-296

Shen WK, ZD Yang, FY Liu (2014). Identification and evaluation of some sugarcane varieties or clones for smut resistance. J Huazhong Agric Univ 33:40-44

Shen WK, ZH Chen, ZD Yang, R Liu, JW Chen, YS Chen (2012). Comparative trials of new sugarcane varieties introduced from Australia. Chin Agric Sci Bull 28:120-125

Shen WK, GH Zhou, HH Deng, LY Zhou (2006). Detection of sugarcane ratoon stunting disease pathogen with PCR and nucleotide sequence analysis. Chin Agric Sci Bull 22:413-416

Sundar AR, EL Barnabas, P Malathi, R Viswanathan (2012). A mini-review on smut disease of sugarcane caused by Sporisorium scitamineum. In: Botany, pp: 109-128. Mworia JK (Ed.). InTech, Croatia

Talukder ZI, BS Hulke, L Qi, BE Scheffler, V Pegadaraju, K McPhee, TJ Gulya (2014). Candidate gene association mapping of sclerotinia stalk rot resistance in sunflower (Helianthus annuиs L.) uncovers the importance of COII homologs. Theor Appl Genet 127:193-209

Tiwari G, R Singh, N Singh, DR Choudhury, R Paliwal, A Kumar, V Gupta (2016). Study of arbitrarily amplified (RAPD and ISSR) and gene targeted (SCoT and CBDP) markers for genetic diversity and population structure in Kalmegh [Andrographis paniculata (Burm. f.) Nees]. Ind Crops Prod 86:1-11

Ukoskit K, G Posudsavang, N Pongsiripat, P Chatwachirawong, P Klomsaard, P Poomipant, S Tragoonrung (2019). Detection and validation of EST-SSR markers associated with sugar-related traits in sugarcane using linkage and association mapping. Genomics 111:1-9
Viswanathan R, GP Rao (2011). Disease scenario and management of major sugarcane diseases in India. Sugar Technol 13:336-353

Wu KK, DJ Heinz, DM Hogarth (1988). Association and heritability of sugarcane smut resistance to races A and B in Hawaii. Theor Appl Genet 75:754-760

Xu GH, QQ Deng, WK Shen, S Chen, XM Wu (2017). Assessment of genetic diversity and structure of Sporisorium scitamineum from China using inter-simple sequence repeat (ISSR) markers. Afr $J$ Biotechnol 16:727-737

Xu L, QW Jiang, J Wu, Y Wang, YQ Gong, XL Wang, C Limera, LW Liu (2014). Identification and molecular mapping of the RsDmR locus conferring resistance to downy mildew at seedling stage in radish (Raphanus sativus L.). J Integr Agric 13:2362-2369

Xu LP, RK Chen (2004). Identification of RAPD marker linked to smut resistance gene in sugarcane. Chin J Appl Environ Biol 10:263-267

Zhang JS, XT Zhang, HB Tang, Q Zhang, XT Hua, XK Ma, F Zhu, T Jones, XG Zhu, J Bowers, CM Wai, C Zheng, Y Shi, S Chen, X Xu, J Yue, DR Nelson, L Huang, Z Li, H Xu, D Zhou, Y Wang, W Hu, J Lin, Y Deng, N Pandey, M Mancini, D Zarpa, JK Nguyen, L Wang, L Yu, Y Xin, L Ge, J Arro, JO Han, S Chakrabarty, M Pushko, W Zhang, Y Ma, P Ma, L Lv, F Chen, G Zheng, J Xu, Z Yang, F Deng, $X$ Chen, Z Liao, X Zhang, Z Lin, H Lin, H Yan, Z Kuang, W Zhong, P Liang, G Wang, Y Yuan, J Shi, J Hou, J Lin, J Jin, P Cao, Q Shen, D Jiang, P Zhou, Y Ma, X Zhang, R Xu, J Liu, Y Zhou, H Jia, Q Ma, R Qi, Z Zhang, J Fang, H Fang, J Song, M Wang, G Dong, G Wang, Z Chen, T Ma, H Liu, SR Dhungana, SE Huss, X Yang, A Sharma, JH Trujillo, MC Martinez, M Hudson, JJ Riascos, M Schuler, LQ Chen, DM Braun, L Li, Q Yu, J Wang, K Wang, MC Schatz, D Heckerman, MAV Sluys, GM Souza, PH Moore, D Sankoff, RB Buren, AH Peterson, C Nagai, R Ming (2018). Allele-defined genome of the autopolyploid sugarcane Saccharum spontaneum $\mathrm{L}$. Nat Genet 50:1565-1578

Zeng B, Y Zhang, LK Huang, XM Jiang, D Luo, G Yin (2014). Genetic diversity of orchardgrass (Dactylis glomerata L.) germplasms with resistance to rust diseases revealed by Start Codon Targeted (SCoT) markers. Biochem Syst Ecol 54:96-102 